\title{
A contribuição da consciência morfológica para a leitura no português brasileiro
}

\author{
Bruno Stefani Ferreira de Oliveira' \\ Universidade Federal de Juiz de Fora, MG, Brasil \\ Francis Ricardo dos Reis Justi \\ Universidade Federal de Juiz de Fora, MG, Brasil
}

\begin{abstract}
Resumo: Neste artigo, avaliou-se a contribuição da consciência morfológica (CM) para a leitura no português brasileiro. Participaram do estudo $|4|$ crianças do $2^{\circ}$ ao $5^{\circ}$ ano do Ensino Fundamental, que foram testadas nas habilidades de leitura, inteligência, memória de trabalho fonológica (MTF), CM e consciência fonológica (CF). Cada criança foi avaliada individualmente em duas sessões de, aproximadamente, 15 minutos. Análises de regressão hierárquica foram realizadas, sendo controladas a idade e a inteligência, enquanto entraram em diferentes momentos na equação as variáveis: CF, MTF e CM. A MTF não contribuiu para a leitura e a $\mathrm{CM}$ contribuiu para a leitura apenas no $4^{\circ}$ e $5^{\circ}$ anos, enquanto a CF contribuiu em todos os anos. Embora a CF tenha contribuído em todos os anos escolares, no $4^{\circ}$ e $5^{\circ}$ anos a contribuição da $\mathrm{CM}$ para a leitura foi maior. Discutiu-se a relevância de se estimular a CM e a CF durante o processo de alfabetização.
\end{abstract}

Palavras-chave: consciência morfológica; consciência morfossintática; leitura; alfabetização; metalinguagem.

\section{THE CONTRIBUTION OF MORPHOLOGICAL AWARENESS TO READING IN BRAZILIAN PORTUGUESE}

\begin{abstract}
The present work evaluated the contribution of morphological awareness for reading in Brazilian Portuguese. One hundred and forty-one Brazilian children from second to fifth Elementary School years took part in this study. We have assessed their reading skills, intelligence, phonological working memory (PWM), morphological awareness (MA), and phonological awareness (PA). Each child was assessed individually in two sessions of fifteen minutes. We have conducted hierarchical regression analyses controlling for intelligence and age with PWM, PA, and MA entering in the investigation in different steps. PWM did not contribute to reading. MA added for reading only in 4th and 5 th years. PA contributed for reading both in 2 nd and 3 rd years and in 4 th and 5 th years. Although PA provided for reading in all school years, MA had a more significant contribution for reading in 4th and 5th years. We have discussed the relevance of including MA and PA stimulation during reading instruction.
\end{abstract}

Keywords: morphological awareness; morphosyntactic awareness; reading; literacy; metalanguage.

\section{LA CONTRIBUCIÓN DE LA CONCIENCIA MORFOLÓGICA PARA LA LECTURA EN PORTUGUÉS BRASILEÑO}

${ }^{1}$ Endereço de correspondência: Bruno Stefani Ferreira de Oliveira; (31) 99378-8321; Rua Maria da Conceição Patrus, 55, Ap. 203, bairro Santa Amélia. Belo Horizonte - MG. CEP 31555-550. E-mail: brunodeoliveirapsi@gmail.com 


\begin{abstract}
Resumen: Se evaluó la contribución de la conciencia morfológica (CM) para la lectura en portugués brasileño. Fueron puestas a prueba las habilidades de lectura, inteligencia, memoria de trabajo fonológica (MTF), CM y conciencia fonológica (CF) de 14 I niños de $2^{\circ}$ al $5^{\circ}$ de enseñanza primaria fundamental. Cada niño fue evaluado individualmente en dos sesiones de aproximadamente 15 minutos. Análisis de regresión jerárquicos fueron realizados, se mantuvo controlada la edad y la inteligencia mientras que entraban en la ecuación en diferentes momentos las variables CF, MTF y CM. entraron en diferentes momentos en la ecuación las variables: CF, MTF y CM. La memoria de trabajo fonológica no contribuyó para la lectura y la conciencia morfológica contribuyó para la lectura apenas en el $4^{\circ}$ y $5^{\circ}$ año; entretanto, la CF contribuyó en todos los años. Aunque la CF contribuyó ha aportado en todos los años escolares, en el $4^{\circ}$ y $5^{\circ}$ año, el aporte de la CM para la lectura fue mayor. Se discute la relevancia de estimular tanto la CM como la CF durante el proceso de alfabetización.
\end{abstract}

Palabras clave: conciencia morfológica; conciencia morfosintáctica; lectura; alfabetización; metalenguaje.

\title{
Introdução
}

Entre as línguas alfabéticas, o grau de correspondência entre as letras e os sons pode variar (Seymour, 2005). No inglês, por exemplo, essa relação é considerada opaca, uma vez que há um número significativo de palavras irregulares, as quais não podem ser lidas apenas pela conversão grafema-fonema. Já em línguas como o português e o espanhol, esse grau de correspondência é maior e a maioria das palavras pode ser lida utilizando-se um processo de conversão entre grafema e fonema, o que torna esses idiomas mais transparentes. No entanto, mesmo em línguas transparentes como o português brasileiro, a morfologia pode ocupar um papel significativo, pois a ortografia de muitas palavras está relacionada à sua raiz (Mota, Anibal, \& Lima, 2008; Silva \& Martins-Reis, 2017). O conhecimento dos morfemas contribui para o entendimento de palavras novas ou irregulares, a partir de generalizações dos afixos e radicais já conhecidos (Guimarães \& Mota, 2016). Por exemplo, mesmo um leitor que até então nunca havia visto ou ouvido a palavra "reexportador" poderia facilmente entender, pela análise dos morfemas, que é referente a alguém que exporta alguma coisa novamente. Assim, a consciência morfológica, habilidade de manipular e refletir sobre as estruturas morfológicas da língua (Carlisle, 1995), pode ser importante para o aprendizado da leitura e da escrita, o que tem levado pesquisadores a investigar essa relação em diferentes línguas (Mota, Anibal, \& Lima, 2008; McBride-Chang, Wagner, Muse, Chow, \& Shu, 2005; Kirby et al., 2012; Angelilli, Marinelli, \& Burani, 2014).

Resultados de um estudo realizado por McBride-Chang et al. (2005) nos Estados Unidos, com 115 crianças pré-escolares e 105 do $2^{\circ}$ ano, demonstraram que a consciência morfológica é uma variável independente da consciência fonológica (habilidade de refletir sobre e de manipular os sons que compõe a fala - Bryant \& Bradley, 1987) e preditora do conhecimento do vocabulário, indicando uma possível relação bidirecional entre as variáveis consciência morfológica e vocabulário. Ou seja, na medida em que crianças adquirem novas palavras, elas são capazes de decompor morfologicamente as palavras de maneira mais rápida, e na medida em que possuem mais conhecimento dos 
morfemas, podem encontrar mais facilidade em entender novas palavras por meio da generalização desses morfemas em novos contextos. Neste estudo, variáveis como o processamento fonológico e a habilidade de leitura de palavras foram controladas.

Kirby et al. (2012) realizaram um estudo longitudinal com 103 crianças a partir do jardim de infância até o $3^{\circ}$ ano. Kirby et al. (2012) analisaram a relação da consciência morfológica com o desenvolvimento da leitura, controlando estatisticamente as variáveis inteligência e consciência fonológica. A Tarefa de Analogia de Palavras foi usada para medir a consciência morfológica durante os anos. Além disso, foram usados testes que avaliaram a inteligência verbal e não verbal, além de tarefas que mediram a consciência fonológica no $1^{\circ}$ ano. Os resultados indicaram que a consciência morfológica das crianças no $2^{\circ}$ e $3^{\circ}$ ano se correlacionou positiva e significativamente com todas as tarefas de leitura. Pela análise de regressão foi possível concluir que houve uma contribuição mais significativa da consciência morfológica para a leitura em crianças do $3^{\circ}$ ano do que de outras faixas etárias; e nas do $2^{\circ}$ ano esse efeito foi pequeno mas significativo, e os resultados das crianças do $1^{\circ}$ não apresentaram relação estatisticamente significativa. $A$ consciência morfológica das crianças no $3^{\circ}$ ano explicou de $3 \%$ a $9 \%$ da variância dos resultados dos testes de leitura, quando as outras variáveis foram controladas.

$\mathrm{Na}$ língua chinesa, que não é alfabética, a consciência morfológica é a variável mais robusta para prever o desempenho de leitura tanto de crianças da pré-escola quanto do $2^{\circ}$ ano do Ensino Fundamental (McBride-Chang, Shu, Zhou, Wat, \& Wagner, 2003). Além disso, na língua chinesa, diferentemente das línguas alfabéticas, a consciência fonológica não desempenha um papel importante na habilidade de leitura (McBride-Chang et al., 2010).

Já é bem estabelecido que a consciência morfológica desempenha um papel importante no aprendizado da leitura em falantes da opaca língua inglesa (Carlisle, 1995; Carlisle, 2003; Kirby et al., 2011; To, Tighe, \& Binder, 2016). Com relação ao português brasileiro, Oliveira \& Justi (2016) realizaram uma recente metanálise com o propósito de mapear e analisar a relação entre a consciência morfológica e o aprendizado da leitura. Foram examinadas todas as pesquisas empíricas indexadas nas principais plataformas acadêmicas que investigaram a relação entre a consciência morfológica e a leitura. Ao serem combinados os dados de todos os 14 estudos que avaliaram essas variáveis, o resultado encontrado foi que, pelo menos, no que diz respeito ao português brasileiro, essa relação ainda não havia sido demonstrada, uma vez que a magnitude de efeito da combinação dos estudos não foi estatisticamente significativa. Um dos problemas apontados pelos autores foi que em muitos desses estudos, que encontram correlações significativas entre consciência morfológica e leitura, não se controlou devidamente o papel do processamento fonológico, o que levaria a uma superestimação do papel da morfologia. Sendo assim, concluem os autores, a contribuição da consciência morfológica, de forma independente, para a leitura ainda carece de comprovação no português brasileiro.

Um dos motivos que poderia explicar a ausência de relação entre a consciência morfológica e a habilidade de leitura no português brasileiro que foi observada na metanálise 
de Oliveira e Justi (2016) é o fato de que a maioria dos estudos realizados no Brasil foi feita com crianças do $2^{\circ}$ e $3^{\circ}$ ano. Uma das hipóteses do presente estudo é que a consciência morfológica passa a desempenhar um papel relevante apenas nos últimos anos do período de alfabetização, uma vez que, nos anos iniciais, na língua portuguesa, o mapeamento grafema/fonema é o mecanismo mais importante para a leitura, sendo a consciência fonológica, neste caso, a habilidade metalinguística fundamental para o bom desempenho dos leitores. Para isso, é necessário que se investigue essa relação em um período maior de desenvolvimento. Além disso, outra constatação da metanálise de Oliveira e Justi foi que, na maioria das vezes, o teste aplicado para aferir a habilidade de leitura era o TDE (Stein, 1994). No entanto, como argumentam Lúcio e Pinheiro (2014), a versão original do subteste de leitura do TDE não possui um bom poder discriminativo entre os bons e maus leitores, apresentando, muitas vezes, efeito de teto nos resultados. Assim, torna-se necessário o uso de um instrumento para a avaliação da leitura que tenha um melhor poder de discriminação entre os bons e maus leitores.

Dessa forma, pode-se dizer que a relação da consciência morfológica com a leitura, referente ao português brasileiro, ainda carece de demonstração e, além disso, pode-se dizer também que essa relação, muitas vezes quando é encontrada, pode se dever à relação que a consciência morfológica tem com as variáveis relacionadas ao processamento fonológico, e não, necessariamente, à suposta relação que a primeira teria com a leitura. Sendo assim, esta pesquisa teve como objetivo verificar a relação entre a consciência morfológica e a leitura em crianças do $2^{\circ}$ ao $5^{\circ}$ ano do Ensino Fundamental, controlando as variáveis relacionadas ao processamento fonológico e utilizando uma versão do TDE com maior poder discriminativo.

\section{Método}

\section{Participantes}

Participaram desta pesquisa 141 crianças do $2^{\circ}$ ( 35 alunos), $3^{\circ}$ (33 alunos), $4^{\circ}$ (33 alunos) e $5^{\circ}$ (40 alunos) anos do Ensino Fundamental. No geral, $51 \%$ dos participantes eram do sexo feminino e possuíam a seguinte média de idade em anos, dentro de cada faixa escolar: $2^{\circ}$ ano, $M=8,0(D P=0,32) ; 3^{\circ}$ ano, $M=8,9(D P=0,41) ; 4^{\circ}$ ano, $M=$ $9,8(D P=0,40) ; 5^{\circ}$ ano, $M=11(D P=0,39)$. Essas crianças estavam matriculadas, regularmente, em duas escolas particulares de uma cidade de médio porte do estado de Minas Gerais e nenhuma delas era repetente. Esta pesquisa foi aprovada pelo Comitê de Ética em Pesquisa de uma universidade federal (número de registro 715.321).

\section{Materiais}

Tarefa de Analogia de Palavras: essa tarefa foi retirada do trabalho de Justi e Roazzi (2012). O participante tinha de identificar a transformação morfológica realizada pelo examinador em um par de palavras e realizar uma transformação semelhante em 
uma palavra-alvo enunciada pelo examinador, seguindo o esquema " $A$ " está para " $B$ " assim como "C" está para "D". Por exemplo, aprendizado-aprender, descoberta-?

Tarefa de Morfossemântica-Raiz: retirada do trabalho de Mota et al. (2008), nesta tarefa é solicitado ao participante que responda qual palavra é formada da mesma forma que determinada palavra-alvo, dentre duas apresentadas como resposta (por exemplo, qual palavra é feita da mesma forma que repensar? Restaurar ou relembrar?).

Subteste de leitura do Teste de Desempenho Escolar - TDE (Stein, 1994): o objetivo deste instrumento é avaliar a habilidade de precisão de leitura. Utilizou-se aqui uma versão modificada do subteste de leitura do TDE conforme sugerido por Lúcio e Pinheiro (2014). Em seu trabalho, Lúcio e Pinheiro realizam uma análise de itens nas palavras do TDE e sugerem, além da adoção de um critério mais estrito de correção, a utilização das palavras do TDE com melhores índices de discriminação. A versão proposta por Lúcio e Pinheiro difere da versão original do TDE ao empregar apenas 25 das 70 palavras do teste original e difere também em relação ao critério de correção, já que na versão proposta são considerados erros as silabações explícitas e as autocorreções, enquanto na versão original isso é permitido. Optou-se pela utilização da versão proposta por Lúcio e Pinheiro porque as pesquisadoras demonstram em seu estudo que essa versão em comparação à original apresenta itens com melhores índices de discriminação, melhor consistência interna e distribuição mais próxima da curva normal.

Tarefa de Subtração de Fonemas: retirada do trabalho de Justi e Roazzi (2012), esta tarefa consiste na apresentação oral de uma palavra (por exemplo, "bola") e o requerimento de que o participante, mentalmente, subtraia um som em particular (por exemplo, /b/) e diga o som que permaneceu (por exemplo, /'ole/).

Tarefa de Spoonerismo: retirada do trabalho de Justi e Roazzi (2012), esta tarefa requer que o participante troque o primeiro som de duas palavras apresentadas um pelo outro (por exemplo, ao se trocar os sons iniciais das palavras /miLU veRdi/se tem /vilLUmeRdi/).

Teste de matrizes progressivas coloridas de Raven (Angeline, Custódio, Duarte \& Duarte, 1999): este teste é composto por figuras com partes ausentes que precisam ser completadas por uma opção correta, a qual está misturada entre outras cinco.

Subteste Dígitos da Escala de Inteligência Wechsler para Crianças - WISC-III (Wechsler, 2002): esta tarefa consiste em repetir uma sequência de dígitos enunciada pelo examinador, ora na ordem direta, ora na ordem inversa.

\section{Procedimentos}

Os participantes realizaram as tarefas em locais reservados pela coordenação de cada escola. A aplicação das tarefas se deu em duas sessões individuais de aproximadamente 15 minutos cada e em dias alternados. Em uma das sessões eram aplicadas as seguintes tarefas: Subteste de leitura, Spoonerismo, Subtração de Fonemas, 
Analogia de Palavras, Decisão Morfossemântica e Subteste de Dígitos WISC. O subteste de leitura e o subteste de Dígitos foram aplicados todas as vezes em primeiro e último lugar, respectivamente. Entre essas tarefas, foram aplicadas as demais em ordem diferenciada e de maneira balanceada. Na outra sessão era aplicado o teste de Raven.

\section{Análise de dados}

Foi utilizado o teste de Kolmogorov-Smirnov para avaliar se os escores das diferentes tarefas apresentaram distribuição normal. Nesse caso, com exceção dos escores da tarefa de Decisão Morfossemântica-Raiz e a tarefa de dígitos no $3^{\circ}$ e $4^{\circ}$ anos, todos os escores das demais tarefas apresentaram distribuição normal. Assim, foram realizadas análises de correlação por ano escolar para as medidas do presente estudo, sendo realizadas análises de correlação de Pearson para os escores das tarefas com distribuição normal e correlação de Spearman quando os escores de uma das tarefas não tinham distribuição normal. Com o objetivo de investigar a contribuição independente da consciência morfológica para a leitura, foram efetuadas análises de regressão hierárquicas tendo como variável critério a leitura e como preditores a consciência fonológica, a memória de trabalho fonológica e a consciência morfológica, sendo controladas a idade e a inteligência não verbal.

\section{Resultados}

Tabela I. Estatísticas descritivas dos resultados das tarefas administradas.

\begin{tabular}{|c|c|c|c|c|c|c|}
\hline Tarefa & Ano (n) & Média & D.P. & Máx. T & Máx. O & Mín. O \\
\hline \multirow{4}{*}{ Leitura/TDE } & $2(35)$ & 7,29 & 5 & 25 & 17 & 0 \\
\hline & $3(33)$ & 14,28 & 4,5 & 25 & 21 & 3 \\
\hline & $4(33)$ & 15,75 & 5,3 & 25 & 25 & 4 \\
\hline & $5(40)$ & 17,38 & 4,5 & 25 & 24 & 4 \\
\hline \multirow{4}{*}{ Analogia de Palavras } & $2(35)$ & 5,74 & 3,1 & 12 & II & 0 \\
\hline & $3(33)$ & 7,03 & 2,5 & 12 & 12 & I \\
\hline & $4(33)$ & 8,34 & 2 & 12 & 12 & 3 \\
\hline & $5(40)$ & 9,33 & 2 & 12 & 12 & 3 \\
\hline
\end{tabular}


Tabela I. Estatísticas descritivas dos resultados das tarefas administradas.

\begin{tabular}{|c|c|c|c|c|c|c|}
\hline Tarefa & Ano (n) & Média & D.P. & Máx. T & Máx. O & Mín. O \\
\hline \multirow{5}{*}{ Decisão } & $2(35)$ & 19,14 & $\mathrm{I}, 4$ & 20 & 20 & 14 \\
\hline & $3(33)$ & 19,59 & $\mathrm{I}, \mathrm{I}$ & 20 & 20 & 14 \\
\hline & & & & & & \\
\hline & $4(33)$ & 19,88 & 0,4 & 20 & 20 & 18 \\
\hline & $5(40)$ & 19,98 & 0,1 & 20 & 20 & 19 \\
\hline \multirow{4}{*}{ Spoone } & $2(35)$ & 10,89 & 6,3 & 20 & 19 & 0 \\
\hline & $3(33)$ & 13,25 & 4,6 & 20 & 20 & 1 \\
\hline & $4(33)$ & $\mid 4,78$ & 5,3 & 20 & 20 & 0 \\
\hline & $5(40)$ & 16,2 & 4,1 & 20 & 20 & I \\
\hline \multirow{4}{*}{ Subtraç } & $2(35)$ & 5,83 & 2,7 & 10 & 10 & 0 \\
\hline & $3(33)$ & 6,34 & 2,5 & 10 & 9 & 1 \\
\hline & $4(33)$ & 7,06 & 1,9 & 10 & 10 & 3 \\
\hline & $5(40)$ & 7,4 & 2,3 & 10 & 10 & 1 \\
\hline \multirow{4}{*}{ Tarefa c } & $2(35)$ & $|0,3|$ & 2,3 & 30 & 15 & 6 \\
\hline & $3(33)$ & 10,28 & 2 & 30 & 18 & 6 \\
\hline & $4(33)$ & 10,59 & 1,6 & 30 & 14 & 6 \\
\hline & $5(40)$ & 11,93 & 2,7 & 30 & 17 & 7 \\
\hline \multirow{4}{*}{ Raven } & $2(35)$ & 25,88 & 5,2 & 36 & 34 & 14 \\
\hline & $3(33)$ & 29,13 & 3,6 & 36 & 34 & 23 \\
\hline & $4(33)$ & 29,75 & 3,5 & 36 & 35 & 20 \\
\hline & $5(40)$ & 31,32 & 3,1 & 36 & 36 & 25 \\
\hline
\end{tabular}

Nota: $\mathrm{n}=$ número de participantes; DP = desvio-padrão; Máx T. = escore máximo possível na tarefa; Máx O. = escore máximo obtido na tarefa; Mín O. = escore mínimo obtido na tarefa.

Fonte: Elaborada pelos autores. 
Como visto na Tabela 1, a tarefa de Decisão Morfossemântica-Raiz claramente apresentou um efeito de teto em todos os anos. Portanto, tal tarefa não foi incluída na análise dos dados. Conforme a Tabela 2, a consciência morfológica não se correlacionou significativamente com a leitura no $2^{\circ}$ e $3^{\circ}$ ano. Já no $4^{\circ}$ e $5^{\circ}$ ano, a correlação dessas variáveis é de $r=0,58(p<0,01)$ e $r=0,51(p<0,01)$, respectivamente.

Tabela 2. Correlações entre a leitura, variáveis metalinguísticas, memória de trabalho e inteligência.

\begin{tabular}{|c|c|c|c|c|c|c|}
\hline & Ano & TDE & An $P$ & Spoo & Sub F & Raven \\
\hline \multirow[t]{4}{*}{ 2. Analogia de Palavras } & 2 & 0,27 & -- & & & \\
\hline & 3 & 0,06 & -- & & & \\
\hline & 4 & $0,58 * *$ & -- & & & \\
\hline & 5 & $0,5 I * *$ & -- & & & \\
\hline \multirow[t]{4}{*}{ 3. Spooneirismo } & 2 & $0,49 * *$ & $0,45 * *$ & -- & & \\
\hline & 3 & $0,63 * *$ & 0,17 & -- & & \\
\hline & 4 & $0,65 * *$ & $0,6 I^{* *}$ & -- & & \\
\hline & 5 & $0,44^{* *}$ & $0,5 I * *$ & -- & & \\
\hline \multirow[t]{4}{*}{ 4. Subtração de Fonemas } & 2 & 0,5 I $* *$ & $0,42 *$ & $0,86 * *$ & -- & \\
\hline & 3 & $0,48 * *$ & 0,10 & $0,72 * *$ & -- & \\
\hline & 4 & $0,46 * *$ & $0,50 * *$ & $0,69 * *$ & -- & \\
\hline & 5 & 0,23 & $0,37^{*}$ & $0,54 * *$ & -- & \\
\hline \multirow[t]{4}{*}{ 5. Tarefa de Dígitos } & 2 & $0,40 *$ & $0,51 * *$ & $0,43 *$ & $0,46 * *$ & -- \\
\hline & 3 & $0,44 *$ & 0,24 & 0,29 & 0,15 & -- \\
\hline & 4 & 0,00 & $0,40 *$ & $0,34^{*}$ & 0,28 & -- \\
\hline & 5 & $0,48 * *$ & 0,18 & 0,26 & 0,15 & -- \\
\hline
\end{tabular}


Tabela 2. Correlações entre a leitura, variáveis metalinguísticas, memória de trabalho e inteligência.

\begin{tabular}{lcccccc}
\hline & Ano & TDE & An P & Spoo & Sub F & Raven \\
\hline 6. Raven & 2 & $\mathbf{0 , 4 8 * *}$ & $\mathbf{0 , 4 5 * *}$ & $\mathbf{0 , 8 0 * *}$ & $\mathbf{0 , 8 1 * *}$ & $\mathbf{0 , 6 3 * *}$ \\
\hline 3 & 0,04 & 0,13 & 0,32 & 0,07 & $-0,27$ \\
\hline 4 & $\mathbf{0 , 5 7 * *}$ & $\mathbf{0 , 6 0 * *}$ & $0,48 * *$ & $\mathbf{0 , 4 8 * *}$ & 0,11 \\
\hline 5 & 0,16 & $-0,02$ & 0,13 & $\mathbf{0 , 3 1 *}$ & 0,03 \\
\hline
\end{tabular}

Nota: $*=p<0,05 ; * *=p<0,0$ I

Fonte: Elaborada pelos autores.

Uma medida de consciência fonológica composta foi criada a partir dos resultados das duas tarefas de consciência fonológica: Spooneirismo e Subtração de Fonemas. A combinação dessas variáveis em uma só medida de consciência fonológica foi feita da seguinte maneira: primeiramente, o valor $z$ para o escore em cada uma das tarefas foi calculado com base na média de toda a amostra; posteriormente, os escores $z$ nas duas tarefas foram somados e a média foi calculada (os escores z nas tarefas de Spooneirismo e Subtração de Fonemas foram somados e o valor resultante foi dividido por dois para se obter a média); finalmente, o escore composto foi repadronizado, ou seja, computou-se, mais uma vez, o escores $z$ para a medida composta.

Tabela 3. Resultados das análises de regressão hierárquica com os preditores de leitura do $2^{\circ}$ e $3^{\circ}$ ano.

\begin{tabular}{llccccc}
\hline \multirow{2}{*}{ Passos } & Variáveis explicativas & \multicolumn{5}{c}{ Variável critério: Leitura/TDE } \\
\cline { 3 - 6 } & & $\mathrm{R} 2$ & $\begin{array}{c}\text { Mudança em } \\
\mathrm{R} 2\end{array}$ & $\begin{array}{c}\text { Mudança em } \\
\text { F }\end{array}$ & Sig. \\
\hline I & Idade & 0,36 & 0,36 & 35,79 & $\mathbf{0 , 0 0}$ & 0,54 \\
\hline 2 & Inteligência & 0,43 & 0,06 & 6,87 & $\mathbf{0 , 0 1}$ & 0,02 \\
\hline 3 & Cons. fonológica & 0,52 & 0,09 & 12,03 & $\mathbf{0 , 0 0}$ & $\mathbf{0 , 3 9 * *}$ \\
\hline
\end{tabular}


Tabela 3. Resultados das análises de regressão hierárquica com os preditores de leitura do $2^{\circ}$ e $3^{\circ}$ ano.

\begin{tabular}{|c|c|c|c|c|c|c|}
\hline \multirow[t]{2}{*}{ Passos } & \multirow[t]{2}{*}{ Variáveis explicativas } & \multicolumn{4}{|c|}{ Variável critério: Leitura/TDE } & \multirow[t]{2}{*}{$\beta$} \\
\hline & & $\mathrm{R} 2$ & $\begin{array}{c}\text { Mudança em } \\
\text { R2 }\end{array}$ & $\begin{array}{c}\text { Mudança em } \\
F\end{array}$ & Sig. & \\
\hline 4 & $\begin{array}{l}\text { Memória de } \\
\text { trabalho }\end{array}$ & 0,52 & 0,00 & 0,54 & 0,46 & 0,08 \\
\hline 5 & Cons. morfológica & 0,53 & 0,00 & 0,37 & 0,54 & 0,06 \\
\hline 3 & Cons. fonológica & 0,52 & 0,09 & 12,03 & 0,00 & \\
\hline 4 & Cons. morfológica & 0,52 & 0,00 & 0,19 & 0,66 & \\
\hline 5 & $\begin{array}{l}\text { Memória de } \\
\text { trabalho }\end{array}$ & 0,53 & 0,00 & 0,72 & 0,39 & \\
\hline 3 & $\begin{array}{l}\text { Memória de } \\
\text { trabalho }\end{array}$ & 0,44 & 0,16 & 1,73 & 0,19 & \\
\hline 4 & Cons. fonológica & 0,52 & 0,08 & 10,49 & 0,00 & \\
\hline 5 & Cons. morfológica & 0,53 & 0,00 & 0,37 & 0,54 & \\
\hline 3 & $\begin{array}{l}\text { Memória de } \\
\text { trabalho }\end{array}$ & 0,44 & 0,16 & $\mathrm{I}, 73$ & 0,19 & \\
\hline 4 & Cons. morfológica & 0,44 & 0,00 & 0,52 & 0,82 & \\
\hline 5 & Cons. fonológica & 0,53 & 0,09 & 10,69 & 0,00 & \\
\hline 3 & Cons. morfológica & 0,43 & 0,00 & 0,00 & 0,92 & \\
\hline 4 & $\begin{array}{l}\text { Memória de } \\
\text { trabalho }\end{array}$ & 0,44 & 0,16 & $\mathrm{I}, 74$ & 0,19 & \\
\hline 5 & Cons. fonológica & 0,53 & 0,09 & 10,69 & 0,00 & \\
\hline
\end{tabular}

Nota: Sig. = nível de significância da mudança em F; $* * *=p<0,0$ I.

Fonte: Elaborada pelos autores.

Nas análises de correlação, a consciência morfológica só teve relação significativa a partir do $4^{\circ}$ ano. Diante disso, realizamos as análises de regressão hierárquica com 
dois recortes de grupo: o primeiro composto pelos dados dos participantes do $2^{\circ}$ e $3^{\circ}$ ano e o segundo por participantes do $4^{\circ}$ e $5^{\circ}$ ano escolar. Com relação ao $2^{\circ}$ e $3^{\circ}$ ano, como se pode ver na Tabela 3, após o controle do efeito das variações de idade e de inteligência, apenas a consciência fonológica é estatisticamente significativa. Mesmo quando essa variável entra no último passo da análise, ela explica $9 \%$ da variação na habilidade de leitura. Quando todas as cinco variáveis foram incluídas na equação regressiva, evidenciou-se uma contribuição independente da consciência fonológica $(\beta=0,40 ; p<0,01)$, mas não da memória de trabalho fonológica $(\beta=0,08 ; p=0,40)$ e nem da consciência morfológica $(\beta=0,06 ; p=0,54)$ para a precisão de leitura.

\section{Tabela 4. Resultados das análises de regressão hierárquica com os preditores de leitura do $4^{\circ}$ e $5^{\circ}$ ano.}

\begin{tabular}{|c|c|c|c|c|c|c|}
\hline \multirow[t]{2}{*}{ Passos } & \multirow[t]{2}{*}{ Variáveis explicativas } & \multicolumn{4}{|c|}{ Variável critério: Leitura/TDE } & \multirow{2}{*}{$\beta$} \\
\hline & & $\mathrm{R} 2$ & $\begin{array}{c}\text { Mudança em } \\
\text { R2 }\end{array}$ & $\begin{array}{c}\text { Mudança em } \\
\text { F }\end{array}$ & Sig. & \\
\hline I & Idade & 0,00 & 0,00 & 0,24 & 0,62 & 0,04 \\
\hline 2 & Inteligência & 0,12 & 0,12 & 9,07 & 0,00 & 0,15 \\
\hline 3 & Cons. fonológica & 0,32 & 0,20 & 19,82 & 0,00 & $0,26 *$ \\
\hline 4 & $\begin{array}{l}\text { Memória de } \\
\text { trabalho }\end{array}$ & 0,35 & 0,02 & 1,90 & 0,17 & 0,13 \\
\hline 5 & Cons. morfológica & 0,45 & 0,10 & 11,15 & 0,00 & $0,37 * *$ \\
\hline 3 & Cons. fonológica & 0,32 & 0,20 & 19,82 & 0,00 & \\
\hline 4 & Cons. morfológica & 0,43 & 0,11 & 12,58 & 0,00 & \\
\hline 5 & $\begin{array}{l}\text { Memória de } \\
\text { trabalho }\end{array}$ & 0,45 & 0,01 & 0,81 & 0,37 & \\
\hline 3 & $\begin{array}{l}\text { Memória de } \\
\text { trabalho }\end{array}$ & 0,20 & 0,08 & 6,40 & 0,01 & \\
\hline 4 & Cons. fonológica & 0,35 & 0,15 & 14,30 & 0,00 & \\
\hline 5 & Cons. morfológica & 0,45 & 0,10 & 11,15 & 0,00 & \\
\hline
\end{tabular}


Tabela 4. Resultados das análises de regressão hierárquica com os preditores de leitura do $4^{\circ}$ e $5^{\circ}$ ano.

\begin{tabular}{|c|c|c|c|c|c|c|}
\hline \multirow[t]{2}{*}{ Passos } & \multirow[t]{2}{*}{ Variáveis explicativas } & \multicolumn{4}{|c|}{ Variável critério: Leitura/TDE } & \multirow{2}{*}{$\beta$} \\
\hline & & $\mathrm{R} 2$ & $\begin{array}{c}\text { Mudança em } \\
\text { R2 }\end{array}$ & $\begin{array}{c}\text { Mudança em } \\
\text { F }\end{array}$ & Sig. & \\
\hline 3 & $\begin{array}{l}\text { Memória de } \\
\text { trabalho }\end{array}$ & 0,20 & 0,08 & 6,40 & 0,0 I & \\
\hline 4 & Cons. morfológica & 0,41 & 0,20 & 21,79 & 0,00 & \\
\hline 5 & Cons. fonológica & 0,45 & 0,04 & 4,69 & 0,03 & \\
\hline 3 & Cons. morfológica & 0,39 & 0,26 & 28,01 & 0,00 & \\
\hline 4 & $\begin{array}{l}\text { Memória de } \\
\text { trabalho }\end{array}$ & 0,41 & 0,02 & $\mathrm{I}, 85$ & 0,18 & \\
\hline 5 & Cons. fonológica & 0,45 & 0,04 & 4,69 & 0,03 & \\
\hline
\end{tabular}

Nota: Sig. = nível de significância em F. $*=p<0,05 ; * *=p<0,0$ I

Fonte: Elaborada pelos autores.

Nas análises realizadas com os participantes do $4^{\circ}$ e $5^{\circ}$ ano, como visto na Tabela 4, após o controle da idade e da inteligência, a consciência morfológica explica $26 \%$ da variação na habilidade de leitura, a consciência fonológica, $20 \%$ e a memória de trabalho, $8 \%$. Mesmo após a entrada da consciência fonológica e da memória de trabaIho na equação regressiva, a consciência morfológica ainda continua a contribuir significativamente com $10 \%$ da variação. Quando a consciência fonológica entra no último passo, ela explica apenas $4 \%$ da variação e a memória de trabalho perde seu poder explicativo ao entrar no derradeiro passo. Quando as cinco variáveis foram incluídas na equação regressiva, evidenciou-se uma contribuição independente da consciência fonológica $(\beta=0,26 ; p=0,03)$ e da consciência morfológica $(\beta=0,37 ; p<0,01)$, mas não da memória de trabalho fonológica $(\beta=0,13 ; p=0,18)$.

\section{Discussão}

A presente pesquisa teve como objetivo analisar a relação entre a consciência morfológica e a leitura em crianças do $2^{\circ}$ ao $5^{\circ}$ ano do Ensino Fundamental. Para tanto, foi aplicada uma versão modificada do subteste de leitura do TDE - corrigida conforme as recomendações de Lúcio e Pinheiro (2014). Além disso, foram realizadas análises 
de regressão hierárquica incluindo as variáveis idade e inteligência como controles e alternando a ordem de entrada na equação das variáveis consciência fonológica, consciência morfológica e memória de trabalho fonológica. Os resultados das análises de regressão indicaram que, quando analisados os dados do $2^{\circ}$ e $3^{\circ}$ anos, a consciência morfológica não contribui de forma independente para a leitura. No entanto, uma análise considerando apenas os dados do $4^{\circ}$ ao $5^{\circ}$ ano mostrou que a consciência morfológica contribui de forma significativa, explicando $10 \%$ da variação da tarefa de leitura. Enquanto no $2^{\circ}$ e $3^{\circ}$ ano a consciência fonológica mostra ter um papel fundamental, a partir do $4^{\circ}$ ano a importância da consciência morfológica ocupa uma função mais expressiva para prever o desempenho na tarefa de leitura.

Este estudo observou um padrão na função das habilidades metalinguísticas no processo de leitura. Miranda e Mota (2013) afirmam que a habilidade de decodificação é a principal habilidade de reconhecimento de palavras, visto que em seu estudo com crianças do $2^{\circ}$ e $3^{\circ}$ ano não encontraram contribuição da consciência morfológica para a leitura. Pode-se dizer que o presente estudo traz dados complementares a essa proposta já que até o $3^{\circ}$ ano, realmente, a consciência fonológica é a principal variável explicativa da competência de leitura. No entanto, à medida que as crianças vão adquirindo mais experiência de leitura, e o $4^{\circ}$ ano parece ser um marco para isso no presente estudo, elas provavelmente passam a depender menos do processo de conversão grafema-fonema para a leitura (embora o papel da consciência fonológica não cesse), e isso abre espaço para a consciência morfológica ocupar um papel mais importante. Uma possível explicação para isso é o fato de que a consciência morfológica pode ajudar no aprendizado do significado de palavras novas, ampliando o vocabulário (McBride-Chang et al., 2005; Miranda \& Mota, 2013) e, consequentemente, ajudando na automatização da leitura por um mapeamento mais direto da ortografia para semântica. Como mostra o estudo de Deacon, Benere e Pasquarella (2013), essa relação também pode ser bidirecional, ou seja, ao ser exposto a cada vez mais palavras (aumento no vocabulário), isso faz com que o leitor perceba as marcações morfológicas das palavras, o que ajuda a desenvolver a consciência morfológica.

Os resultados do presente estudo também ajudam a entender os achados da metanálise de Oliveira e Justi (2016). Nesse caso, o fato de os autores não terem encontrado evidências da contribuição da consciência morfológica para a leitura no português brasileiro possivelmente se deve à questão de haver um fator relacionado ao ano escolar das amostras dos estudos incluídos na metanálise. A metanálise incluiu dados de estudos realizados com crianças de diferentes anos escolares, e, inclusive, a maior parte dos estudos abarcava participantes do $2^{\circ}$ ao $3^{\circ}$ ano do Ensino Fundamental. No entanto, como visto nesta pesquisa, a consciência morfológica começa a mostrar sua contribuição apenas a partir do $4^{\circ}$ ano. Quando apenas os dados do $2^{\circ}$ e $3^{\circ}$ ano são analisados conjuntamente, a contribuição para a leitura não é percebida. Ou seja, considerando os resultados do presente estudo, mesmo que as pesquisas computadas na metanálise tivessem usado testes de leitura mais precisos, possivelmente essa rela- 
ção não teria sido encontrada, uma vez que a maioria de tais estudos foi feita com crianças do $2^{\circ}$ ao $3^{\circ}$ ano.

Estudos realizados com crianças na língua inglesa têm achado contribuições da morfologia para a leitura em crianças a partir do $3^{\circ}$ ano (Carlisle, 1995; Deacon, Benere, \& Pasquarella, 2013). Talvez as peculiaridades da língua inglesa, como a opacidade, demandem de crianças o desenvolvimento da habilidade metalinguística de manipular morfemas numa idade mais precoce do que as crianças falantes do português, que, por possuírem uma língua mais transparente, se servem por um período mais longo apenas da consciência fonológica.

Pelos resultados apresentados na presente pesquisa, dois pontos precisam ser destacados sobre a relação da consciência morfológica com a leitura. O primeiro é a relevância de analisar os dados separadamente a partir do $4^{\circ}$ ano escolar, quando a consciência morfológica tem um papel importante para a leitura. No entanto, esse simples recorte não seria suficiente para indicar a relação entre essas variáveis, pois Justi e Roazzi (2012) aplicaram as mesmas tarefas de consciência morfológica, consciência fonológica, memória de trabalho fonológica e inteligência em crianças do $4^{\circ}$ ano e não encontraram contribuição significativa da consciência morfológica para a leitura. Ou seja, há um segundo ponto nessa divergência de resultados, e, o que tudo indica, confirma a hipótese dos pesquisadores de que o problema poderia estar também na medida de leitura. No estudo de Justi e Roazzi (2012), foi usada a forma original de correção do TDE que é mais fácil que a versão utilizada no presente estudo. Dessa forma, é possível que a versão do TDE utilizada por Justi e Roazzi tenha apresentado menos capacidade de discriminar entre bons e maus leitores e isso tenha prejudicado a análise da contribuição da consciência morfológica para a leitura nas séries mais avançadas. Além disso, neste estudo, a análise foi feita com crianças no final do $4^{\circ}$ e do $5^{\circ}$ ano, ou seja, os participantes do presente estudo também tinham mais experiência de leitura.

\section{Conclusão}

Os resultados do presente estudo evidenciam que enquanto no $2^{\circ}$ e $3^{\circ}$ ano da amostra investigada a consciência fonológica mostra ter um papel fundamental para o desempenho na leitura, a partir do $4^{\circ}$ ano, a consciência morfológica passa a apresentar uma contribuição mais expressiva para a habilidade de leitura. Esses resultados possuem tanto contribuições teóricas quanto práticas. A contribuição da consciência morfológica para a leitura a partir do $4^{\circ}$ e $5^{\circ}$ ano reforça a ideia de que é importante que os profissionais do campo da alfabetização considerem a estimulação da consciência morfológica como uma parte importante do processo de alfabetização. Tendo a consciência morfológica uma contribuição independente, pode-se pensar que alguns leitores possam ter dificuldades na leitura por causa de limitações em sua capacidade de manipular as palavras no nível dos morfemas, carecendo, portanto, de 
intervenções pedagógicas pontuais. Dessa forma, a avaliação e a estimulação dessa habilidade em sala de aula tornam-se importantes, haja vista a sua relação com a habilidade de leitura.

Este estudo lança luz à compreensão da relação da consciência morfológica com a leitura no português brasileiro em alguns pontos significativos: ela responde à lacuna levantada na metanálise de Oliveira e Justi (2016) relativa à boa parte dos estudos no país que não controlou variáveis importantes em relação à leitura e que foram realizados majoritariamente com crianças do $2^{\circ}$ e $3^{\circ}$ ano. Além disso, este estudo, ao usar uma medida de leitura mais precisa, atende ao problema levantado por Miranda e Mota (2013) e Justi e Roazzi (2012) em relação à limitação da versão original do TDE.

Pode-se destacar como limitação deste trabalho o fato de ter-se usado apenas uma medida da principal variável do estudo, a consciência morfológica, uma vez que o teste de decisão morfossemântica-raiz, por apresentar efeito de teto, não foi utilizado nas análises. Além disso, a presente pesquisa limitou sua amostra às escolas particulares, o que abre uma lacuna para saber se os mesmos resultados seriam encontrados com participantes de escolas públicas. Uma contribuição importante para pesquisas futuras seria a realização de estudos longitudinais, de forma que seja possível acompanhar o desenvolvimento da consciência morfológica e sua relação com a leitura no português brasileiro.

\section{Referências}

Angelilli, P., Marinelli, C. V., \& Burani, C. (2014). The effect of morphology on spelling and reading accuracy: a study on Italian children. Fronteirs in Psychology, 5(1373), 1-12. doi: 10.3389/fpsyg.2014.01373

Angelini, A., Alves, I., Custódio, E., Duarte, W., \& Duarte, J. (1999). Manual matrizes progressivas coloridas de Raven: escala especial. São Paulo: Centro Editor de Testes e Pesquisas em Psicologia.

Bryant, P., \& Bradley, L. (1987). Problemas de leitura na criança. Porto Alegre, RS: Artes Médicas.

Carlisle, J. F. (1995). Morphological awareness and early reading achievement. In: L. Feldman (Ed.). Morphological aspects of language processing (pp. 189-209). Hillsdale, NJ: Erlbaum.

Deacon, S. H., Benere, J., \& Pasquerella, A. (2013). Reciprocal relationship: Children's morphological awareness and their reading accuracy across grade 2 to 3. Developmental Psychology, 49(6), 1113-1126. doi: 10.1037/a0029474

Guimarães, S. B., \& Mota, M. M. P. E. (2016). Qual a contribuição da consciência morfológica das crianças na precisão de leitura de palavras e compreensão de 
texto no português?. Estudos de Psicologia (Natal), 21(3), 239-248. doi: $10.5935 / 1678-4669.20160023$

Justi, C. N. G., \& Roazzi, A. (2012). A Contribuição de Variáveis Cognitivas para a Leitura e a Escrita no Português Brasileiro. Psicologia: Reflexão e Crítica, 25(3), 605-614. doi: 10.1590/S0102-79722012000300021

Kirby, J. R., Deacon, S. L., Bowers, P. N., Izenberg, L., Wade-Wooley, L., \& Parrila. R. (2012) Children's morphological awareness and reading ability. Read Writ, 25, 389-410. doi: 10.1007/s11145-010-9276-5

Lúcio, P. S., \& Pinheiro, A. M. V. (2014). Novos estudos psicométricos para o subteste de leiturado teste de desempenho escolar. Temas em Psicologia (Ribeirão Preto), 22, 109-119. doi: 10.9788/TP2014.1-09

McBride-Chang, C., Shu, H., Zhou, A., Wat, C. \& Wagner, R. (2003). Morphological Awareness Uniquely Predicts Young Children's Chinese Character Recognition. Journal of Educational Psychology, 95, 743-751. doi: 10.1037/0022-0663.95.4.743.

Mcbride-Chang, C., Wagner, R. K., Muse, A., Chow, B. W., \& Shu, H. U. A. (2005). The role of morphological awareness in children's vocabulary acquisition in English. Applied Psycholinguistics, 26(3), 415-435. doi: 10.1017/S014271640505023X

McBride-Chang, C., Lam, F., Lam, C., Chan, B., Fong, C., Wong, T., \& Wong, S. (2011). Early predictors of dyslexia in Chinese children: familial history of dyslexia, Ianguage delay, and cognitive profiles: Early predictors of dyslexia in Chinese children. Journal of child psychology and psychiatry, and allied disciplines, 52, 20411. doi: 10.1111/j.1469-7610.2010.02299.x

Mota, M., Annibal, L., \& Lima, S. (2008). A Morfologia derivacional contribui para a leitura e escrita no português? Psicologia: Reflexão e Crítica, 21(2), 311-318. doi: 10.1590/S0102-79722008000200017

Miranda, L. \& Mota, M. M. P. (2013) Consciência Morfológica e Reconhecimento de Palavras. Psico-USF, Bragança Paulista, 18(2), 241-248. doi: 10.5380/psi.v15i1.15654

Oliveira, B. S. F. \& Justi, F. R. R. (2016). Uma meta-análise da relação entre a consciência morfológica e a leitura e escrita no português brasileiro. In: Pereira-Silva, N. L., Barbosa, A. J. G., Rodrigues, M. C. (Orgs.). Pesquisa em desenvolvimento humano e educação (pp. 19-38). Curitiba: CRV.

Silva, A. A. M. \& Martins-Reis, V. O. (2017). Influência da consciência morfológica na leitura e na escrita: uma revisão sistemática de literatura. CoDAS, 29(1), 1-8. doi: 10.1590/2317-1782/20172016032

Stein, L. (1994). TDE: Teste de Desempenho Escolar: manual para aplicação e interpretação. São Paulo: Casa do Psicólogo. 
Seymour, P. H. K. (2005). Early Reading Development in European Orthographies. In M. J. Snowling \& C. Hulme (Eds.), Blackwell handbooks of developmental psychology. The science of reading: A handbook (pp. 296-315). http://dx.doi. org/10.1002/9780470757642.ch16

To, N. L., Tighe, E. L., \& Binder, K. S. (2016). Investigating morphological awareness and the processing of transparent and opaque words in adults with low literacy skills and in skilled readers. Journal of Research in Reading, 39(2), 171-188. doi: 10.1111/1467-9817.12036

Wechsler, D. (2002). WISC-III: Escala de inteligência Wechsler para crianças. Manual (3. ed., V. L. M. de Figueiredo, adaptação e padronização brasileira). São Paulo, SP: Casa do Psicólogo.

Submissão: 17.10.2016

Aceite: 18.8.2017 